\title{
The Effect of Keyword and Context Methods on Vocabulary Retention of Iranian EFL Learners
}

\author{
Hassan Soleimani, Ph.D. (Corresponding author) \\ Department of Applied Linguistics, Payame Noor University, PO box 19395-3697. Tehran, Iran \\ E-mail: arshia.soleimani@gmail.com
}

Maryam Saeedi

MA in TEFL, Payame Noor University, Iran

Reza Mohajernia

MA in TEFL, Najafabad Azad University, Iran

Received: 11-05- 2012

doi:10.7575/ijalel.v.1n.2p.49
Accepted: 12-06- 2012

Published: 01-07- 2012

URL: http://dx.doi.org/10.7575/ijalel.v.1n.2p.49

\begin{abstract}
This study intended to investigate the comparative effectiveness of keyword and context method on immediate and delayed vocabulary retention of EFL learners. It also compared the rate of forgetting in the keyword and context groups. With a quasi experimental design, 40 learners from two intact classes in a language teaching institute in Khorramabad, Iran, were randomly assigned to the keyword and context group. The keyword group received the keyword strategy training, while the context group focused on learning vocabulary in their real context. The result indicated that learners in the keyword group recalled more vocabulary immediately after training and one week later. The results also indicated the rate of forgetting is more in the context group than in the keyword group.
\end{abstract}

Key words: Vocabulary Learning, Keyword Strategy, Context Strategy, Vocabulary Retention

\section{Introduction}

According to Wilkins (1972), without grammar very little can be conveyed, without vocabulary, nothing can be conveyed. To many students, memorizing long vocabulary lists can be boring, time-consuming, and ineffective. Thus, the effectiveness of vocabulary learning methods is a very important element in first language (L1) and second language (L2) pedagogy.

One of the most studied foreign language vocabulary teaching method has been the keyword method (Rodridguez \& Sadoski, 2000; Pressley, Levin, \& Delanely, 1982). Keyword strategy may trace back to the empirical support of Paivio's (1997) Duel-Coding Theory (Rodriguez \& Sadoski, 2000; Shapiro \& Waters, 2005). According to Shapiro and Waters (2005), words are stored in two different coding systems in Dual-Coding Theory with different levels of processing ranging from shallow to deep. Shallow processing focuses on surface features of words to be remembered such as sound, physical feature and so on. Deep processing focuses on meaning. Keyword strategy associates the meaning, sound, and image of L1 and L2 to improve retention ( Hulstijin, 1997; Level \& Miller, 1982).

Recent studies examined the effect of the keyword method on second/foreign language vocabulary learning. It was found that keyword strategy has a significant effect on vocabulary acquisition and retention (Rodriguez \& Sadoski, 2000; Levin \& Pressely, 1985).

Another effective vocabulary learning strategy is the context method. The context method helps learners learn words' meaning through the meaning of a sentence as a whole. Many researchers examined the effects of context method on vocabulary acquisition and retention. Some demonstrate the facilitating effects of context on word recognition (Redouane, 2004; Nash and Snowling, 2006). Liu and Nation (1985) claim context method as a complex and often difficult strategy to carry out.

Page 49 
This study compares not only the effects of the keyword and context method on immediate and long-term vocabulary retention by Iranian learners who had been studying English for less than one year, but also the rate of forgetting across the groups.

\subsection{Critical review}

Atkinson (1975) has developed keyword strategy for foreign vocabulary learning. It was a mnemonic technique in which a new word is associated to a similar sounding familiar word, or keyword. Then, a mental image is formed to link the unfamiliar word to the keyword. The keyword strategy is an interesting tool for acquiring English vocabularies (Chen, 2006). Hall, Wilson, and Patterson (1981) have claimed that the keyword method is the most useful to less experienced learners, such as the young. They also found that keywords provided by experimenter yielded better recall than when participants were required to create their own keyword.

Nash and Snowlling (2006) found that the context method increases vocabulary knowledge and improves reading comprehension in children with poor existing vocabulary knowledge. Kuhn (1998) suggested that a vast majority of words do not become part of students' reading vocabulary, through direct instruction but incidentally by encountering them in text. Redouane (2004) found that the guessing-from-context technique proved to have an impact not only on immediate recall but on long-term retention.

\subsection{Review of related Studies}

Baleghizadeh and Ashoori (2010) examined the comparative effects of the word list and the keyword method on immediate retention of English words under classroom condition by Iranian junior high school students. The participants were 44 females at the elementary level of English language proficiency from 2 intact classes from one school in Asatra, Iran. The two classes were randomly assigned to the word list group and the keyword group. The participants had been studying English for maximum of two years. On the recall test, the participants in the keyword group outperformed the participants in the word list on the total number of items answered correctly immediately after instruction.

Rodrigues and Sadoski (2000) examined the effects of rote rehearsal, context, keyword, and context-keyword on immediate and long-term retention of EFL vocabulary in natural classroom setting. The participants were 16 ninth-grade students from 8 intact EFL from two different classes in Trujila, Venezuela. The students had been studying for more than two years. The immediate performance of the participants using the combined context/keyword method was significantly better than that of students using keyword method. After a week, the combined context/keyword method was significantly better than all other method.

\section{Method}

\section{1 Hypothesis and questions}

Examining the related literature, the present study aims to answer the following three questions.

Question 1: Will there be any difference in the vocabulary knowledge between the keyword instruction and the context method instruction immediately after training?

H1: Training in the keyword strategy will affect the immediate vocabulary retention more significantly than training in the context method.

Question 2: Will there be any difference in the vocabulary knowledge between the keyword instruction and the context instruction?

H2: Training in the keyword strategy will affect the long-term vocabulary retention more significantly than training in the context method.

Question 3: Will there be any difference in the rate of forgetting between the keyword instruction and the context instruction?

\subsection{Research design}

Two intact classes were assigned to the keyword group and context group. The keyword group received keyword method training; while the context group involved in context vocabulary instruction including reading texts, repeating, and translating intended words. Students' vocabulary knowledge was tested immediately after the second session treatment and one week later for both the keyword and the context group.

\subsection{Participants}


International Journal of Applied Linguistics \& English Literature

ISSN 2200-3592 (Print), ISSN 2200-3452 (Online)

Vol. 1 No. 2; July 2012

The participants were selected from a language teaching institute in Khorramabad, Iran. They had not studied English at school as a course before. They were studying the first book of Let's Go at the institute. The subjects were homogeneous in their English language proficiency (beginners) with their age range from 8 to 11 . The two intact classes were randomly assigned to the keyword group and the context group. The keyword group included 20 learners, 10 female and 10 male students. The context group included 20 learners, 10 girls and 10 boys. Two experienced female instructors were selected for this study. Table 1 shows the demographic distribution of the two groups.

Table 1. Demographic Table of Participants

\begin{tabular}{llcc}
\hline Group & Gender & Range Age & Total Participants \\
\hline Keyword & Male & 8 to 11 & $\mathrm{n}=5$ \\
& Female & 8 to 11 & $\mathrm{n}=15$ \\
Context & Male & 8 to 11 & $\mathrm{n}=8$ \\
& Female & 8 to 11 & $\mathrm{n}=12$ \\
& & $\mathrm{~N}=40$
\end{tabular}

\subsection{Materials}

30 words were selected as materials for this study at first. We deleted 10 words from the list to which the subjects were already exposed, so the word list was reduced to 20 low-frequency words for the subjects. A list of 10 words, Persian keywords and their Persian translation, was presented to the keyword group at the first session (Appendix A). Other 10 words were presented to the keyword group in the same way at the second session one day later (Appendix A). Each session lasted 30 minutes.

As for the context group, the instructor selected two texts including the same 20 words presented to the keyword group (Appendix B). The first text included 10 words from the word list presented to the context group at the first session. Other texts were presented at the second session. Each session lasted 30 minutes. A test sheet included all the 20 words was provided, listing each vocabulary word and allowing space for the learners to write their meaning in Persian (Appendix C). The test sheet was given to both group subjects immediately after the second instruction session and also one week later.

\subsection{Procedure}

As mentioned earlier, two intact classes, each consisting of 20 male and female learners, were randomly assigned to the keyword group and the context group. The experiment was conducted at two sessions. A list of 20 English words with Persian keyword and two texts including the same 20 words were prepared. We consulted the teachers of the two classes to be sure that the participants had encountered none of the target words prior to experiment.

A total of 20 words along Persian keywords and their Persian translations were presented to the keyword group. For example, the English word "child" is connected to Persian keyword "chai" which means tea. After presenting each target word, along with a similar sounding word in Persian, and its Persian translation, the instructor said a sentence including both the foreign word and the keyword. Then she helped them imagine a mental image including both the native word and the keyword group. The experiment was conducted at two sessions (10 words each session). Each session lasted 30 minutes.

The context group subjects were introduced to the same 20 lexical words, presented to the keyword group, in their actual contexts. Only one exposure was considered optimal to each target word. The instructor read a text. When she introduced the intended words, she talked about its meaning in Persian and asked students to repeat the word and its meaning several times. This experiment was also conducted at two sessions (10 words each session) of 30 minutes.

At the end of the second session, a test of all the English words learned in the two experimental sessions was administered to the keyword group participants and the context group participants to determine the effect of the two types of instructions on short-term retention of vocabularies. Again, the same test was given them to test their vocabulary knowledge one week later to determine the effect of the two type of instructions on long-term retention of vocabularies. The test was a list of vocabulary items and sufficient space for the learners to write their meaning in Persian at 15 minutes. The participants' scores were obtained by adding up the correct answers. Each participant's score fluctuated between 0 and 20.

Page $\mid 51$ 
International Journal of Applied Linguistics \& English Literature

ISSN 2200-3592 (Print), ISSN 2200-3452 (Online)

Vol. 1 No. 2; July 2012

\section{Result}

This study examined the comparative effects of the keyword and context method on immediate and long-term vocabulary retention by Iranian junior learners who had been studying English for less than one year. All students of both the keyword group and the context group were given a vocabulary achievement test right after the end of the two-session teaching program. Results of the analysis of the immediate test scores of the keyword and context group are reported in Table 2. The table shows that learners in the keyword group scored higher on the immediate test than the learners in the context group (Median=19.25 and 15.5 respectively). The keyword group's immediate test mean score was also higher than that for the context group (Mean=18.55 and 16.2 respectively) with large variation within the context group in their test scores (the keyword $S D=1.79$ and context $S D=2.71$.

Table 2. The Keyword and Context Groups' Performance on the Immediate Test

\begin{tabular}{cccccc}
\hline Group & $M$ & Med & SD & Std. Error & Range Score \\
\hline Keyword & 18.55 & 19.25 & 1.79 & .73 & $15-20$ \\
Context & 16.2 & 15.5 & 2.71 & & $10-20$ \\
\hline
\end{tabular}

df $=38 \quad t$-critic $=1.67 \quad p \leq .05 \quad t$-obs $=3.22$

Results of the independent sample $t$-test indicate a significant differences between the keyword and context group's mean scores measured immediately after the two instructional sessions $(t=3.22, d f=38, \mathrm{p} \leq .05)$. This indicates that the keyword group performed better on immediate test than the context group. As a whole, the keyword group recalled more target vocabulary immediately after training than the context group.

In addition, all students of both groups, the keyword group and the context group, were given the same vocabulary achievement test one week after the two instructional sessions. The results presented in Table 3 show that learners in the keyword group scored higher on the test than did the learners in the context group $($ Med.$=18$ and 13.5 respectively). The keyword group's one week after training test mean scores was also higher than that for the context group $(M=18.20$ and 14.55) with larger variation within the context group in their test score (the keyword group $S D=1.90$ and the context group $S D=3$ ).

Table 3. The Keyword and Context Group's Performance on One week after Training Test

\begin{tabular}{cccccc}
\hline Group & $M$ & Med. & SD & Std. Error & Range Score \\
\hline Keyword & 18.20 & 18 & 1.90 & .79 & $15-20$ \\
Context & 14.55 & 13.5 & 3 & $10-20$ \\
\hline$d f=38 \quad t$-critic $=1.68$ & $p \leq .05$ & $t$-obs $=4.62$ & &
\end{tabular}

Results of the independent sample $t$-test indicate a significant difference between the keyword group and context group mean's scores in vocabulary acquisition $(t=4.62$, df $=38, \mathrm{p} \leq \quad .05 \quad)$. This indicates that the keyword group scored higher than the context group on the test as a result of using keyword instruction for vocabulary learning. As a whole the keyword group recalled more target vocabulary one week after training than the context group.

As Table 4 displays, the mean difference between the keyword group's mean scores measured immediately after training and one week later is not significant $(t=.35, d f=38, p \leq .05)$. But the mean difference between the context group's mean scores measured immediately after training and one week later is merely significant $(d f=$ $38, t=1.75, p \leq .05)$. This indicates that the keyword group performed well on both immediate test and one week after training test. But the context group performed better on immediate test than on test one week after training. 
International Journal of Applied Linguistics \& English Literature

ISSN 2200-3592 (Print), ISSN 2200-3452 (Online)

Vol. 1 No. 2; July 2012

Table 4. The Difference on the Scores between the Keyword and Context Group Immediately One Week after Training

\begin{tabular}{ccccc}
\hline Group & Test & Mean Difference & Std. Error & $T$ \\
\hline Keyword & $\begin{array}{c}\text { Immediate/ } \\
\text { one-week later test } \\
\text { Context }\end{array}$ & $\begin{array}{c}\text { Immediate/ } \\
\text { one-week later test }\end{array}$ & 1.65 & .58 \\
\hline
\end{tabular}

As a whole the keyword group retained more vocabulary knowledge one week after training than did the context group. The rate of forgetting is less in the keyword group than in the context group.

\section{Discussion}

The purpose of this research was to compare the effect of keyword strategy and context method on short-term and long-term vocabulary retention. The research also compared the rate of forgetting in the keyword group and context group. Overall, the results support the hypotheses that test the comparative effect of keyword strategy and context method on the immediate and long-term vocabulary retention.

Hypothesis 1 examined the comparative effect of keyword strategy and context method on short-term vocabulary retention. As it has been mentioned in the result section, a $t$-test was conducted immediately after training to examine the comparative effectiveness of keyword strategy and context method on immediate vocabulary retention. A significant difference was found between the keyword and context groups in vocabulary achievement as measured by the immediate test after training. The keyword group recalled more target vocabulary as a result of exposure to the keyword instruction. The result supports hypothesis 1 that predicts the keyword strategy is more effective than the context method in immediate vocabulary retention.

Hypothesis 2 examined the comparative effect of the keyword strategy and the context method on long-term vocabulary retention. A $t$-test was conducted one week after training to compare the effectiveness of the keyword and context group. Again, a significant difference was found between the keyword group and context group in vocabulary achievement as measured by the test one week after training. The keyword group performed more significantly on the test than did the context group as a result of exposure to the keyword instruction. This means that use of keyword strategy improves learners' vocabulary achievement and retention. The result supports hypothesis 2 that predicts the keyword group perform more significantly than do the context group.

One aim of the study was to compare the rate of forgetting in the keyword group and the context group. The mean difference between the keyword group's scores on the immediate test and one week later test is less than the mean difference between the context group' s scores on the immediate test and one week later test. This indicates that the rate of forgetting is lower in the keyword group than the context group. This means that when learners learn and memorize vocabularies through keyword instruction, they only forget a few of them later. But learners who learn or memorize vocabularies through the context method, they forget a lot of the vocabularies later.

The finding that the learners in the keyword group significantly recalled more target words than did the context group right after the treatment and one week after the treatment is consistent with previous researchers' finding that indicated the effectiveness of the keyword method in vocabulary memorization (Rodriguez \& Sadoski, 2000; Baleghizadeh \& Ashoori; McDaniel \& Pressley, 1987; Chen, 2006; McDaniel \&Pressley, 1984). The finding that indicate the context group recalled less target vocabularies than did the keyword group is consistent with previous researchers' finding that reliance upon context clues to unlock the meaning of unfamiliar words can be problematic (Beck, Mckeown, \& McCaslin, 1983; Kameenui, Carnine, \& Ferschi, 1982; Frantzen, 2003).

There are several limitations in this study. One of the limitations in this study is related to the two vocabulary learning methods. Although the keyword strategy is an effective method for facilitating learning and memorizing vocabulary, this method cannot be applied for teaching all vocabulary items. The keyword strategy is inapplicable to teaching abstract vocabularies. As some researchers believe the context method is often considered as a very difficult strategy to carry out successfully because of the following problems: it is imprecise; it is time-consuming; it is highly depends on text difficulty and learners' level; even if it leads to comprehension, it may not lead to acquisition (Coady \& Hulkin, 1999). 
International Journal of Applied Linguistics \& English Literature

ISSN 2200-3592 (Print), ISSN 2200-3452 (Online)

Vol. 1 No. 2; July 2012

Another limitation is related to the participants. A few of the participants in the keyword group did not follow the keyword instruction. In the same way, some learners in the context group may have used other strategies such as repetition for vocabulary memorization.

Since many factors such as age and previous knowledge have been supposed to affect the effectiveness of the keyword method (Hall, Wilson, \& Patterson, 1981), the use of relatively small sample size and participants with a limited age range of 8 to 11 is considered as a limitation to this study as well.

This research results indicate that the keyword strategy might raise learners' performance. Although the finding indicates a significant mean difference between the keyword group and the context group, the context method is also a good vocabulary strategy. It can be used when the keyword strategy is inapplicable. As a whole it was recommended that teachers make use of a variety of vocabulary learning methods for teaching foreign vocabularies.

\section{References}

Atkinson, R. C. (1975). Mnemonics in second language learning. American Psychologist. 30, 821-828.

Baleghizadeh, S., \& Ashoori, A. (2010). The effect of keyword and word list on immediate vocabulary retention of EFL learners. Pakistan Journal of Social Sciences (PJSS). Vol. 30, No.2, 251-261.

Beck, I., Mckeown, M. G. \& McCaslin, E. S. (1983). Vocabulary development: All contexts are not created equal. Elementary School Journal, 83, 177-181.

Chen, Y. M. (2006). The effect of keyword method on English vocabulary long-term retention of elementary school students in Taiwan. Unpublished Master Thesis. Department of Applied English, Southern Taiwan University.

Frantzen, D. (2003). Factors affecting how L2 Spanish students derive meaning from context: A meta-analysis. Review of Educational Research,68, 450-469.

Hulstijn, J. H. (1997). Mnemonic methods in foreign language vocabulary learning: Theoretical considerations and pedagogical implication. In J. Coady and T. Hulkin (Eds, 1999), Second Language Acquisition: A Rationale for Pedegogy. Cambridge: Cambridge University Press.

Kameenui, E. J., Carnine, D. W., \& Ferschi, R.(1982). Effects of text construction and instructional procedures for teaching word meanings on comprehension and recall. Reading Research Quarterly, 17, 367-388.

Kuhn, M. \& Stahl, S. (1998). Teaching children to learn word meaning from context: A synthesis and some questions (Electronic Version). Journal of Literacy Research.

Levin, J. R., McCormik, G. B., Berry, J. K., \& Pressley, M. (1982). Mnemonic versus non-mnemonic vocabulary learning strategies for children. American Educational Research Journal, 19, 121-136.

McDaniel, M. A. \& Pressley, M. (1984). Putting the keyword method in context. Journal Educational Psychology, 76, 598-609.

McDaniel, M. A. and Pressley, M. (1987). Imagery and related mnemonic processes: theories, individual differences, and applications. New York: Springer-Verlag.

Nash, H., \& Snowling, M. (2006). Teaching new words to children with poor existing vocabulary knowledge: A controlled evaluation of the definition and context method. International Journal of Language and Communication Disorders, 41, 335-354.

Pressely, M., Levin, J. R. \& Delaney, H. D. (1982). The mnemonic keyword method. Review of Educational Research, 52, 61-91.

Redouane, R.(2004). Assessing institutional method in L2 French vocabulary acquisition: Guessing-from-context method versus a word-list method. Retrieved from http://homepage.mac.com/Tefftennant/welfa/WELFA.

Rodriguez, M., \& Sadoski, M. (2000). Effects of rote, context, keyword, and context/keyword methods on retention of vocabulary in EFL classrooms. Language Learning, 50, 385-412.

Shapiro, A. M \& Waters, D. L(2005). An investigation of the cognitive processes underlying the keyword method of foreign vocabulary learning. Language Learning, 9, 55-88.

Page $\mid 54$ 
International Journal of Applied Linguistics \& English Literature

ISSN 2200-3592 (Print), ISSN 2200-3452 (Online)

Vol. 1 No. 2; July 2012

\section{APPENDIX A}

The booklets given to all members of the keyword group at the two instructional sessions

Booklet one

\begin{tabular}{|c|c|c|}
\hline English & Persian & Keyword \\
\hline House & خانه & حوض \\
\hline Room & اتاق & اروم \\
\hline Child & بجه & جاى \\
\hline Girl & دختر & كل \\
\hline Cookie & كلوجه & كوكى \\
\hline Tea & جاى & تير \\
\hline Watch & ساعت مجى & ماج \\
\hline Shoe & كفش & شور \\
\hline Knife & جاقو & ناف \\
\hline Food & غذا & فوت كردن \\
\hline
\end{tabular}

Booklet two

\begin{tabular}{|c|c|c|}
\hline English & Persian & Keyword \\
\hline Zoo & باغ وحش & زور \\
\hline Cook & بختن & كوى كردن \\
\hline Noon & ظهر & نون \\
\hline Sea & دريا & سىى \\
\hline Ship & كثنى & شيب \\
\hline Lock & فقل كردن & لاك \\
\hline Peach & هلو & بيج \\
\hline Moon & ماه & مو \\
\hline Glass & ليوان & كيلاس \\
\hline Blond & طلايى & بلند \\
\hline
\end{tabular}

\section{APPENDIX B}

Texts given to all members of the context group to learn the words in their actual contexts

\section{Text 1}

My aunt lives in a big house. Her house has five rooms. She lives with her child. Her child is a short girl with blond hair. They eat cookies and drinks tea every day. Today is her child's birthday. She gives her a watch and red shoes. Her child cut cake with a knife. She is 7 years old now. They are very happy.

\section{Text 2}

Ted works in a zoo. He gives animals their food and cooks food for other men every noon. He goes to a sea near the zoo and looks at ships every evening. He locks doors every night, then sits under a peach tree and looks at moon. Every morning he drinks only a glass of milk and starts working.

\section{APPENDIX C}

The test sheet for keyword and context groups immediately after training and one week later

\section{Achievement test}

Name:

Class:

Date:

Write each word's Persian definition in front of it.

\begin{tabular}{|ll|ll|ll|ll|}
\hline 1. & Blond $=$ & 2. & Lock $=$ & 3. & Girl $=$ & 4. & Zoo $=$ \\
\hline 5. & Glass $=$ & 6. & Sea $=$ & 7. & Cookie $=$ & 8. & Knife $=$ \\
\hline 9. & Peach $=$ & 10. & Moon $=$ & 11. & Room $=$ & 12. & Food $=$ \\
\hline 13. & Short $=$ & 14. & House $=$ & 15. & Watch $=$ & 16. & Child $=$ \\
\hline 17. & Ship $=$ & 18. & Tea $=$ & 19. & Shoe $=$ & 20. & Noon $=$ \\
\hline
\end{tabular}

